\title{
Research on the Countermeasures of Tianjin Financial Service Innovation
}

\author{
Tao $\mathrm{Ma}^{1, a}$ \\ ${ }^{1}$ Tianjin University of Finance \& Economics, Tianjin, China \\ amatao_work@126.com
}

Keywords: Tianjin, science and technology finance, service innovation, countermeasures.

\begin{abstract}
While facing the ever-changing scientific and technological changes and the constraints of the increasingly tightened resources and environment, the international competition characterized by innovation and technological upgrading has become more and more intense. The financing ability of domestic small and medium-sized scientific and technological enterprises is weak. The existing models of science and technology finance cannot meet the needs of the development of the small and medium-sized scientific and technological enterprises, which has become the bottleneck that affects and restricts the enterprises' core competitiveness and the China's overall strength of science and technology. This paper explores into the science and technology financial services in Tianjin, analyzes its present situation, problems and causes and puts forward the countermeasures to promote the innovation of science and technology finance in China.
\end{abstract}

\section{The Existing Problems in Tianjin's Financial Services of Science and Technology}

The policy supervision system of the government administration department needs to be improved. Lacking systematic financing policy which is based on the enterprises' stepwise development

Small and medium-sized scientific and technological enterprises have different characteristics in the different stages of their development and have different needs of financing. Although some policies have been issued, such as technology giants, innovation funds, guarantees and pledged loans, these policies for the enterprises' different development stages is lack of systematization.

The implementation of the policy is not in place and the financial support needs to be strengthened

Banks, venture capital centers, guarantee companies and other financial institutions need to obtain the corporates' real information. However, the financial institutions have not shared information with the Science and Technology Commission, department of industry and commerce, department of taxation and other relevant departments. The discounts, guarantees and incentive policies provided by the government are not in place.

The security system is not perfect and the collateral effect of guaranty funds is not strong enough

Being the safeguard measure of the small and medium-sized scientific and technological enterprises' financing, it mainly relies on the guaranty companies supported by the government, such as Haitai Guaranty Company. However, the problems still exist, for instance, the capital is insufficient; the guaranty funds of each district is scattered and it is difficult to exert its agglomeration effect.

The financing of the intellectual property pledge is difficult. [1] Although the government has made great efforts to promote the financing of intellectual property pledge and gain greater achievements, the risk is difficult to control and the enterprises and banks participating in it are not limited. Compared to the total financing demand of Tianjin science and technology, it is not enough.

The financial intermediary information and services is not perfect. The asymmetry information between banks and enterprises. The financial institutions are not familiar to the actual situation and requirements of the scientific and technological enterprises that need funds in Tianjin. Thus, they cannot provide these enterprises with appropriate financial products.

The enthusiasm of financial institutions is not high. The small and medium-sized scientific and technological enterprises lack effective collateral assets and have difficulties in the realization of 
intellectual property assets. In addition, the low interest on loans and high risks all cause the result that the financial institutions are not enthusiastic about lending to the scientific and technological enterprises.

The lack of guaranty funds makes it difficult to play a gathering effect. On the one hand, the government-invested guaranty companies are under-capitalized. The existing policy stipulates that the guarantee balance should be controlled at 10 times of the net assets of the guaranty company, which leads to the phenomenon that the guaranty companies are unable to undertake more guarantees because of the lack of funds. On the other hand, the guaranty funds in districts and counties are decentralized and the clustering effect is weak. And the banks do not trust the private guaranty companies.

The lack of the small businesses' risk assessment means. The credit rating system of the scientific and technological enterprises is not completed. Thus, the financial institutions cannot objectively and truly master the credit status of the enterprises. They lack the knowledge and experience of the valuation of intellectual property value and risk assessment, which leads to the financial institutions are quite cautious to the scientific and technological enterprises' loans.

\section{Analysis on the Causes of Problems in Tianjin's Science and Technology Financial Services}

Through the investigation, it is found that the reasons leading to these problems can be classified into three aspects, the government, the financial institutions and the enterprises.

The government's functions and responsibilities are unclear. Due to the imperfect market environment and the excessive administrative management, the financial institutions' enthusiasm for technology financial services is not enough. The government is concerned about the small and micro enterprises and lacks the continuous and perfect system of policy supporting. The imperfect security system is mainly due to the lack of the institutional innovation system and the imperfect market mechanism, resulting in the problems of the government-funded security and the private capital guarantee.

The communication and information platform between the enterprises and banks established by the government is not enough, which causes the information asymmetry. The banks cannot accurately assess the risks of the enterprises and are less active. The risks and incomes of the pledged loans are unequal. The policy funds provided by the government are insufficient or delayed, which has also affected the incentives of the financial institutions.

The financial information platform is not completed. At present, the most prominent problem in the science and technology finance of Tianjin is that the banks require the enterprises to provide collateral (or pledge) or guarantee while the enterprises lack collateral (or pledge) or guarantee.

Due to the information asymmetry, the financial intermediaries are not familiar to the basic situation of the scientific and technological enterprises and their demands. Thus, they cannot dock with the enterprises to provide them with the appropriate financial products.

The credit rating system of scientific and technological enterprises is not completed. Thus, the financial institutions cannot objectively and truly understand the credit status of the enterprises, not identify and pass on the risks to the scientific and technological enterprises.

According to the traditional collateral and guarantee, the scientific and technological enterprises lack the effective collateral assets while the security companies have the financial constraints. Thereby, this has become the bottleneck of the financial services in technology.

The enterprises lack the awareness of financing. On the one hand, the scientific and technological enterprises' leaders are not aware of the importance of policy and financial product information on reducing the enterprises' financing cost of and obtaining the development funds. They have not concentrated on it. On the other hand, the correct interpretation of the government's policy and the full understanding of the financial product, and the in-depth contact with the financial institutions all require professional talents. The scientific and technological enterprises may lack the financial and management personnel. They have not paid much attention to it. 


\section{To Promote the Innovation of Tianjin's Science and Technology Financial Services}

In view of the existing problems and causes of Tianjin's financial services, drawing on the experience of the developed countries and the actual situation of Tianjin, the paper combines with the financing characteristics of Tianjin's small and medium-sized scientific and technological enterprises and puts forward a financial services innovation mode with the main subject of the market and with the main purpose of cultivating the famous enterprises. This mode is guided and supported by the government through the seed period, the start-up period, the development period and the growth period.

To play the role of macro-government guidance. Make clear the objectives and functional orientations. To increase support for innovation in science and technology financial services. In the technological financial services system, the small and medium-sized enterprises' 12 billion in their start-up period and 8 billion in their growth period should be rationally used and timely and appropriately allocate some of the financial funds to establish the science and technology innovation fund, so that we can strengthen the financial supporting for the financial services of science and technology and strive to increase with an average annual growth of $10 \%$.

To strengthen the propaganda and training of the scientific and technological innovation. The government should increase the propaganda of the small and medium-sized scientific and technological enterprises and the venture capital. We should enhance the people's understanding of venture capital, issue the regulations of the venture capital management as soon as possible, introduce a series of preferential policies to improve the legal environment and policy environment for investment and introduce more venture capitalists. In addition, in the face of the forums, seminars and training courses with different levels held by different groups, we should timely sum up new experiences and approaches and solve the common problems in financial services. The city-wide financial and technical personnel training can be carries out, focusing on training the compound talents with the knowledge of science and technology, finance, marketing, enterprise development and so on and establishing a financial team with comprehensive business ability.

To strengthen the enforcement of intellectual property protection. In the face of the international situation, China should not only protect the abroad intellectual property rights, but also for protect the domestic research institutions and enterprises' intellectual property rights and legitimate rights and interests. At present, the most important is to strengthen the law enforcement, crack down on illegal behavior of intellectual property infringement.

To improve the guaranty and risk compensation mechanism. To increase policy support for the guaranty agencies

On one hand, it is suggested to increase the proportion of investment in government-sponsored guaranty companies or to extract some funds from the existing specialized funds to compensate for compensatory losses of policy guarantees and to enhance the guaranty companies' ability of resisting risks. On the other hand, the scattered security funds in different districts and counties should be integrated to focus on larger and stronger powerful guaranty company.

To actively develop various forms of guaranty institutions. In the implementation of the government's specialized guaranty fund and the active form the policy guaranty institutions, we should make the best use of the leverage of the government's specialized guaranty fund, fully mobilize the enthusiasm of private capital, encourage private capital to flow into the guaranty market, form the commercial guaranty institutions and establish the credit re-guaranty institutions for small and medium-sized enterprises as soon as possible. The implementation of business guidance and supervision of the credit guarantee institutions can be carried out in the small and medium-sized enterprises, so that we can carry out the general re-guaranty and compulsory re-guaranty, strengthen the guaranty agencies risk ability, eliminate the hidden dangers of financial institutions and enhance the cooperation.

To guide the guaranty agencies to improve their service level. The local governments should actively coordinate the relationship between the credit guaranty institutions and the banks. It is suggested that the local financial authorities or re-guaranty institutions sign a framework agreement with the cooperating banks to guide the financial institutions according to the guaranty institutions' 
credit levels, capital scale and operating performance. And we should also gradually expand the proportion of the guarantee to improve the risk-sharing ratio, lower the guaranty interest rate, optimize the project operating procedures, improve the working efficiency and improve the loan guarantee service system.

To establish the risk compensation mechanism of the guaranty institution as soon as possible. First, we need to establish the credit guaranty institutions within the risk control mechanism to strengthen their dynamic tracking and supervision and to strengthen claims recovery.

Second, we need to establish the credit guaranty institutions within the risk compensation mechanism to timely establish the risk reserves. In accordance with the agreed responsibilities, fulfill the debt to the creditor banks on behalf of the guaranty enterprises.

Third, we need to establish the credit guaranty institutions with risk-sharing and transfer mechanism to enhance the responsibility of owners and managers to prevent the guaranteed enterprises from escaping risk and transferring debt.

To promote the development of patent circulation centers. To give full play to the advantages of the government's concentration of great event, the patent circulation center with the government's fund, the banks' transfer and the universities and research institutes' assessment is excepted. If the banks are unable to repay the loan of the scientific and technological enterprises' projects with prospective development, they can transfer them to the universities and research institutes' transferring center with higher evaluation level to conduct the patent specialization and development prospects assessment. For the prospective patens, the transferring center can repurchase and integrate this patent, and then put it into market transactions. The institution explores into the business mode which is based on the marketization and specialization and an enterprise's operation, so that we can achieve the win-win construction goal of the government, the social capital and the scientific and technological enterprises.

To promote intellectual property securitization. The securitization of intellectual property is an asset-oriented financing way, which breaks through the limitation of the traditional financing and solves the problem of the small and medium-sized scientific and technological enterprises' financing difficulty. [2] China's asset securitization is still in the initial stage, which is a government-led securitization mode. In order to speed up the implementation of intellectual property securitization for small and medium-sized scientific and technological enterprises in China, in accordance with the document named Guidance Opinion on Accelerating the Cultivation and Development of Intellectual Property Rights Service jointly issued by the State Intellectual Property Office and other departments, the specialized intellectual property securitization authority should be established to strengthen the financial supervision mechanism and cultivate the market trading system which is suitable for the securitization of intellectual property rights.

To improve the investment operation mechanism of innovation fund. The small and medium-sized scientific and technological enterprises lack the spirit of continuous innovation and development potential. It is more difficult for the government innovation fund to choose a good project. To create a good external environment for the operation of the innovation fund through the promotion of training, the network can be used to expand the impact of innovation fund. [3] We can continually improve the existing management of the innovation fund to strengthen its effectiveness and encourage the innovation development, which remains to be solved by the government.

To optimize the financial intermediary service structure. To strengthen the construction of the information resources sharing platform. The small and medium-sized scientific and technological enterprises' database should not only reflect the scientific and technological financial services parties to the common requirements of the science and technology enterprises' information, but also focus on the individual characteristics of different evaluation subjects, different industries and different scientific and technological enterprises at all stages of development. It is suggested that the financial intermediaries and relevant government departments should consult and construct information resource sharing platform to disclose the relevant scientific and technological enterprises' information in certain scope. Thus, they can make it become the information access and means of the science and 
technology financial services' value evaluation and risk identification and provide suggestions for the financial and technical services.

To improve the various forms of technology financial services. To actively cultivate the venture capital that meets the market's demand. We can establish the venture investment institutions with private investment and market operation, encourage and support the cooperation with developed areas of science and technology finance to form the regional venture capital organizations, establish the Sino-foreign joint venture or the foreign-owned capital institutions, make the full use of overseas funds, talents and advanced management experience and promote the development of China's venture capital industry.

To improve the intermediary service agencies' risk investment. We can improve the high-tech industry's risk investment evaluation and consulting institutions. The accounting firms, law firms, patent offices and other service agencies should strictly evaluate the investment projects, reduce the venture capital's technology risk as soon as possible. We can also establish an efficient information network by using the modern information means to strengthen the researches on the domestic and international technology market and the economic and technological forecasts, improve the decision-making level of risk investment, enhance resilience and gain better benefits.

To innovate the scientific and technological enterprises' financial leasing services. Based on the existing services provided by China's finance leasing companies, we will provide more financing products for the small and medium-sized enterprises' projects, appropriately adjust the examination and approval procedures in the policy scope, reduce the relevant expenses and innovate the leasing and financing business of the small and medium-sized scientific and technological enterprises.

To regulate the pawn financing. Pawn financing mainly engages in microfinance business. Pawn line has not too much cumbersome procedures nor restrictions and its operation processes are relatively simple, which has been the small and medium-sized enterprises' rapid financing green channel. At the same time, China needs to regulate the market supervision system, adjust the market accessing threshold, adjust the pawn business scope and improve the pawn industry rules, which will make it better for China's financial services.

To strengthen the guaranty institutions' quality construction. First, through the guaranty industry trade associations, we can improve the industry standards and the supervision and management practices, strengthen the industry self-discipline and standardize the service behaviors.

Second, the guaranty institutions can establish and improve the modern enterprise system, innovate the service guarantees, expand the guaranty scope and enhance the enterprises' strength.

Third, through the methods of introducing the talents, strengthening the training, enhancing the cooperation and exchanges, we can continue to improve the professional staff's quality and their professional level and enhance their business management capabilities.

Fourth, the guaranty agencies need to take a variety of ways to continuously expand the total capital, mobilize more enterprises and even individual industrial and commercial households participate in it, increase accumulation, enhance the strength and improve the ability to resist risks.

To strengthen the financial (intermediary) agency personnel's training. The relevant business training is required for the personnel of the financial institutions, the assessment institutions and other relevant departments. Thus, we can raise the personnel's awareness of the importance of the financial services and improve the standardized business level of the basic theories, risk identification and value assessment of the science and technology finance. The financial institutions should quickly become familiar with the technology financial product innovation mode and understand it and strengthen the assessment and business supervision of the financial risks.

\section{References}

[1] B.Y. Zhang, Research on pledge financing of IPR , J. Intellectual Property. 3 (2009) 30-34.

[2] Z.G. Yu, K.H. Qiu, Z.H. Yu, Studies on Chinese IP securitization theory and developing strategy, J. Studies in Science of Science.6 (2007) 1077-1082. 
[3] B.H. Yue, H.C. Wang, L. Xie, Study on the investing system of innovation fund for technology based firm -- transformation from supporting system to investing system, J. Science of Science and Management of S.\&T. 9 (2007) 59-64. 